\title{
Educação e diversidade cultural: culturas indígenas e africanas na sala de aula
}

Education and cultural diversity: indigen and african cultures at the class

\author{
Márcia Solange Volkmer \\ Ana Paula Castoldi \\ Élin Regina Westenhofen \\ Jéssica Riedi \\ Júlia Leite Gregory \\ Marina Johann
}

Centro Universitário UNIVATES - UNIVATES - Lajeado - Rio Grande do Sul - Brasil

\begin{abstract}
Resumo: Este artigo apresenta algumas ações e reflexões desenvolvidas no âmbito do Programa Institucional de Bolsas de Iniciação à Docência referentes ao estudo da diversidade cultural no contexto escolar. Inserido em um projeto de ocupação do território e desenvolvimento da agricultura no Brasil, o Vale do Taquari, na região central do Rio Grande do Sul, foi ocupado por imigrantes que cruzaram o Atlântico no século XIX. Esse movimento caracterizou um processo que fez surgir na região uma concepção histórica que não reconhece a presença de outros grupos sociais como igualmente formadores da sociedade local. No currículo das escolas da região, isso também é percebido. Nesse sentido, entende-se que o estudo do patrimônio cultural pode contribuir para a percepção da diversidade dos grupos sociais que participam da realidade local. Entendendo-se a cultura como patrimônio, e os processos de patrimonialização como escolhas políticas, foi elaborado um projeto para possibilitar o contato e o diálogo intercultural na escola, estudando a história e culturas indígenas e africanas. Assim, ao conhecer saberes e práticas culturalmente distintas, há o reconhecimento da diferença.A prática pedagógica foi orientada com o objetivo de permitir o diálogo intercultural, rompendo com posições preconceituosas.
\end{abstract}

Palavras-chave: Educação. História. Cultura.

Abstract: The present essay presents some actions and reflections developed within the Scholarship Program of Introduction to Teaching (PIBID) relative to the study of cultural diversity in the school context. Inserted on a project for the territory's occupation and agricultural development in Brazil, the Taquari's Valley, at the central region of the state of Rio Grande do Sul, was occupied by immigrants that crossed the Atlantic Ocean at the 19th century. This movement characterized a process which gave rise in the region to an historical conception that doesn't recognize the presence of another social groups as equally formers of the local society. In the schools' curricula of the region, that fact is also perceived. In this sense, it is understood that the study of the cultural heritage may contribute for the perception of the diversity of the social groups that participate in the local reality. Understanding the culture as heritage, and the patrimonialization processes as political choices, a project was elaborated to allow the intercultural contact and dialogue at the school, studying the Indigen and African history and culture. That way, knowing culturally distinct wisdom and practices, the difference is recognized. The pedagogical practice was oriented with the goal of allowing the intercultural dialogue, breaking preconceived positions.

Keywords: Education. History. Culture. 


\section{Introdução}

O Brasil é um país culturalmente diverso que reconheceu positivamente a sua diversidade em um passado histórico bastante recente. Nos projetos de constituição da nação, as populações indígenas e africanasnão foram consideradas como integrantes do perfil de população que se buscava. No transcurso do século XIX, quando o território brasileiro tinha sido conquistado e suas fronteiras definidas, buscava-se completar o projeto povoando essas extensas regiões. Nesse processo, na busca de "civilidade", atenção maior foi dada aos imigrantes europeus, e não houve a integração social dos povos indígenas, mestiços ou escravizados.

$\mathrm{Na}$ transição do século XIX para o século $X X$, quando a República brasileira projeta o seu ideal de nacionalidade, pontua-se que a cultura do país é diversificada; no entanto, almeja-se uma homogeneização. Naquele período, com base nas ideias do evolucionismo social, vigente há décadas na Europa, projeta-se um país branco (VIOTTI DA COSTA, 1999). Nesse contexto, no qual a miscigenação é incentivada, a cultura europeia e dos imigrantes europeus ganha primazia sobre os demais grupos sociais (SEYFERTH, 1996).Essa concepção, que torna positiva a presença dos imigrantes brancos no país, e aposta no processo de miscigenação como a possibilidade de alterar "a cara e a cor" do Brasil, está presente ainda nas décadas de 1940 e 1950, quando a historiografia chega a caracterizar a existência de uma "democracia racial" no país. Constitui-se uma visão de integração total das distintas etnias, com o apagamento da presença negra e indígena, e afirma-se a inexistência do preconceito.

Quando os primeiros esforços de constituição do patrimônio cultural do Brasil são mobilizados, na década de 1930, prevalece a demarcação dos bens materiais associados ao grupo branco e economicamente bem posicionado. A diversidade cultural brasileira só passa a ser assegurada efetivamente com a Constituição de 1988, que em seu Artigo 215 estabelece que "§ 1. O Estado protegerá as manifestações das culturas populares, indígenas e afro-brasileiras, e das de outros grupos participantes do processo civilizatório nacional". A partir desse momento, novas políticas culturais são definidas e novos grupos sociais ganham visibilidade no campo histórico-cultural e patrimonial.

Como esse processo é bastante recente no país, ainda carecemos de referenciais que efetivamente permitam o reconhecimento da história, cultura e identidade das distintas etnias na configuração sociocultural brasileira. Essa marginalização de alguns grupos é ainda mais acentuada em regiões nas quais a participação do elemento colonizador branco foi hegemônica, como nas colônias de imigração do sul do país, que incluem - Vale do Taquari. Por isso, a importância de se promover uma educação intercultural.

Um documento da UNESCO, a "Declaração
sobre raça e sobre preconceitos raciais", de
1978, foi um dos primeiros textos a propor os
conceitos fundantes da educação intercultural.
A Declaração afirma que "todos os povos e
todos os grupos humanos, qualquer que seja
a sua composição ou a sua origem étnica,
contribuem conforme sua própria índole para
o progresso das civilizações e das culturas,
que, na sua pluralidade e em virtude de sua
interpretação, constituem o patrimônio comum
da humanidade" (UNESCO, 1978, APUD
FLEURI, 2001, p.51)

As questões interculturais podem assumir variadas perspectivas e múltiplos olhares pedagógicos e epistemológicos. Parte-se da premissa do reconhecimento de distintos grupos e da sua efetiva interação. Há o reconhecimento da intencionalidade dos sujeitos envolvidos no processo histórico e, no campo educativo, há o interesse também na promoção de novas relações. Entende-se que a sociedade não é homogênea, que a cultura é um processo dinâmico e que as identidades individuais e coletivas devem ser compreendidas em suas múltiplas manifestações.

A escola, por sua vez, funciona como parte integrante da sociedade, compreendida entre a diversidade individual e coletiva, em uma dinâmica fundamentada na pluralidade. Partindo desse pressuposto acredita-se ser de grande importânciao 
incentivo a uma educação voltada para o respeito às diferenças epossuidora de um caráter multicultural, para que haja transformação social (LORENZET; CARPENEDO, 2012). Ou seja, para que exista uma sociedade igualitária, livre de preconceitos e discriminações, é preciso, por meio da educação, superar o conhecimento acumulativo e incentivar o pensamento crítico e coletivo.

O multiculturalismo entende que cada grupo social desenvolve certas características pelas quais se identifica, em relação com o outro (LORENZET; CARPENEDO, 2012). Em sua concepção original, a expressão multiculturalismo designa "a coexistência de formas culturais ou de grupos caracterizados por culturas diferentes no seio das sociedades modernas" (KRETZMANN, 2007, p.14). O multiculturalismo é uma questão extremamente complexa na contemporaneidade, vinculada às lutas pela afirmação do direito à diferença e ao processo de globalização. No Brasil, como destaca Kretzmann (2007),busca-se hoje a delimitação de um patrimônio histórico e cultural nacional, que considere a presença dos distintos grupos sociais brasileiros. No entanto, alguns grupos ainda são privilegiados.

Para o sociológico Darcy Ribeiro, o Brasil não é fruto da evolução de formas anteriores de sociabilidades, mas, sim, produto da concentração de uma força de trabalho escrava, subjugada a processos violentos de ordenação e repressão, criando assim, um distanciamento social entre a população em geral e uma minoria privilegiada, isolada na indiferença. Para Kretzmann (2007) o reconhecimento dos negros e dos indígenas pelo Estado favorece a afirmação do pluralismo étnico, imprescindível para que se crie uma ideia adequada da importância das diferentes etnias e do respeito às suas diferenças.

Destaca-se a importância do reconhecimento das comunidades étnicas participantes do processo de criação da sociedade brasileira. Pois, ainda segundo Darcy Ribeiro, vê-se no Brasil uma unidade étnica, que apesar da confluência de matrizes variadas (portugueses, negros africanos e índios americanos) em sua formação, se constitui em uma etnia nacional, nas palavras do autor, em um "estado uni étnico".Fleuri (2003) destaca a importância da compreensão do processo histórico de formação nacional. Para ele, o Brasil é historicamente uma sociedade multiétnica, tendo em sua base uma imensa diversidade de culturas. Ao reconhecermos nossa diversidade étnica, passamos a ter clareza dos fatores constitutivos de nossas identidades sociais, compreendendo que estes não se caracterizam por uma estabilidade e fixação naturais.Assim, "as identidades culturais - aqueles aspectos de nossas identidades que surgem de nosso pertencimento a culturas étnicas, raciais, linguísticas, religiosas, nacionais - sofrem contínuos deslocamentos ou descontinuidades". (FLEURI, 2003, p. 24).

Da mesma forma, Canen e Oliveira (2002) acreditam que o projeto multicultural insere-se na visão pós-moderna de sociedade, na qual a diversidade, a descontinuidade e a diferença são percebidas como categorias centrais. Especificamente no caso da educação e formação de professores em sociedades multiculturais como o Brasil, os autores acreditam que o multiculturalismo crítico deve ser assumido como norteador nos discursos curriculares e nas práticas. Sobre o papel da educação intercultural enquanto reconhecimento do direito à diferença individual e coletiva, os autores dissertam:

\footnotetext{
Uma dupla dimensão caracteriza a educação multicultural: de um lado, a necessidade de promovermos a equidade educacional, valorizando as culturas dos alunos e colaborando para a superação do fracasso escolar. Por outro, a quebra de preconceitos contra aqueles percebidos como "diferentes", de modo que se formem futuras gerações nos valores de respeito e apreciação à pluralidade cultural, e de desafio a discursos preconceituosos que constroem as diferenças. (CANEN E OLIVEIRA, 2002, p.63)
}

Seguindo essa perspectiva os processos educativos tornam-se fundamentais.Com base no diálogo estabelecido por Canen e Oliveira (2002) existem três categorias centrais nas práticas pedagógicas multiculturais. A primeira delas está relacionada à crítica cultural, como a possibilidade dada aos estudantes de analisar identidades étnicas, 
criticar mitos sociais, o incentivo à tomada de posições e ações efetivas, visando o desenvolvimento de conhecimentos plurais através de atividades democráticas em sala de aula. A segunda categoria diz respeito à hibridização discursiva realizada por intermédio da estratégia, denominada pelos autores como ancoragem social, que significa realizar em conjunto com os estudantes conexões entre discursos históricos, políticos, culturais, sociológicos, entre outros.

Realizar essas conexões significa olhar criticamente para percepções e ideias relativas a conhecimento, educação, formação docente e outras categorias, analisando as presenças e ausências nesses discursos, entendendo-os como intimamente ligados a dinâmicas sociais, culturais e históricas, que passam a ser objeto de discussão(CANEN E OLIVEIRA, 2002, p.64).

No caso do Brasil, como destaca Kretzmann (2007), a disputa multicultural está enraizada no processo histórico de formação de um país caracterizado por processos de conquista e colonização, seguidos de uma política de apropriação forçada e de eliminação da identidade das comunidades tradicionais. Em linhas gerais, a construção democrática e a afirmação dos direitos humanos estão diretamente relacionadas ao diálogo intercultural.

Sacavino (2012) assinala alguns desafios fundamentais para a promoção da educação intercultural, crítica e emancipatória. Entre eles está a necessidade de desconstrução dos preconceitos, estereótipos que povoam o imaginário individual e coletivo, e que também caracterizam o ambiente escolar. Deve-se questionar as "intolerâncias já naturalizadas", e o caráter monocultural e etnocêntrico, que saturam os currículos escolares.

Outra preocupação destacada por Sacavino (2012) se relaciona com a articulação entre igualdade e diferença em relação às políticas educativas e práticas pedagógicas, além do resgatedos processos de construção das identidades socioculturais. Devese, assim, promover experiências de interação sistemática com diferentes modos de vida, expressão e organização social. A autorareafirma também a importância dos processos defortalecimento dos atores sociais, tidos historicamente como minorias. Sendo assim, considera fundamental vincular propostas de educação intercultural à políticas públicas, nas quais, na maioria dos casos,impera o mito e o desconhecimento do outro. Ou seja, trata-se da construção de uma educação escolar frente aos desafios da sociedade contemporânea.

Nessa perspectiva, concordamos com CANDAU (2008) que propõe "um multiculturalismo aberto e interativo, que acentua a interculturalidade, por considerá-la a mais adequada para a construção de sociedades, democráticas e inclusivas, que articulem políticas de igualdade com políticas de identidade." Para a autora, "as relações culturais não são relações idílicas; estão construídas na história e, portanto, estão atravessadas por questões de poder, por relações hierarquizadas, marcadas pelo preconceito e pela discriminação de determinados grupos". (CANDAU, 2008, p.51).

A perspectiva intercultural que defendo quer
promoveruma educação para o o
reconhecimento do "outro",para o diálogo
entre os diferentes grupos sociaise culturais.
Uma educação para a negociação cultural,que
enfrenta os conflitos provocados
pelaassimetria de poder entre os diferentes
grupos socioculturaisnas nossas sociedades e
é capaz de favorecera construção de um
projeto comum, pelo qualas diferenças sejam
dialeticamente integradas.
perspectivaintercultural está orientada à
construção deuma sociedade democrática,
plural, humana, que articulepolíticas de
igualdade com políticas de identidade.
(CANDAU, 2008, p.52)

Para finalizar, destaca-se o importante papel do educador nos debates interculturais em educação. Almeja-se a construção de uma educação escolar frente aos desafios da sociedade contemporânea, em uma proposta de educação para a alteridade (FLEURI, 2003, p. 43).

\section{A diversidade cultural na sala de aula}

Com a promulgação da Lei 11.645 , de 10 de março de 2008, alteram-se as Diretrizes e Bases da 
educação nacional, e o tema da diversidade cultural chega às salas de aula, estabelecendo:

"Art. 26-A. Nos estabelecimentos de ensino fundamental e de ensino médio, públicos e privados, torna-se obrigatório o estudo da história e cultura afro-brasileira e indígena. § 10 O conteúdo programático a que se refere este artigo incluirá diversos aspectos da história e da cultura que caracterizam a formação da população brasileira, a partir desses dois grupos étnicos, tais como o estudo da história da África e dos africanos, a luta dos negros e dos povos indígenas no Brasil, a cultura negra e indígena brasileira e o negro e o índio na formação da sociedade nacional, resgatando as suas contribuições nas áreas social, econômica e política, pertinentes à história do Brasil. § 20 Os conteúdos referentes à história e cultura afrobrasileira e dos povos indígenas brasileiros serão ministrados no âmbito de todo o currículo escolar, em especial nas áreas de educação artística e de literatura e história brasileiras."

A temática da diversidade cultural já tinha sido evidenciada nos Parâmetros Curriculares Nacionais e, neste ano de 2015, ganha nova centralidade no texto da Base Nacional Comum Curricular. A mesma propõe como princípio para a área de História "identificar, problematizar e emitir opiniões sobre as causas da exclusão social de migrantes de diferentes procedências, povos indígenas e afro-brasileiros, no tempo presente", o que vem ao encontro do proposto no projeto desenvolvido.

O reconhecimento da importância cultural dos grupos negros e indígenas, no entanto, foi um processo bastante lento no país. Somente na década de 1980, motivados pelas ações dos movimentos sociais, é que alguns reconhecimentos se deram no aspecto legal. As lutas e os movimentos sociais, portanto, foram importantes para que o tema hoje esteja presente na legislação.

Nesse processo, teve centralidade 0 Movimento Negro Unificado (MNU), que surge em 1978 em São Paulo. Esse movimento surgiu em uma manifestação nas escadarias do Teatro Municipal de São Paulo que reuniu milhares de pessoas para protestar contra os crimes raciais. O Movimento Negro Unificado criou, alguns meses depois do ato público, uma "Carta", em que reivindicava uma reavaliação do papel do negro para a história do país e a valorização dessa cultura. (PEREIRA, 2012) Esse movimento é considerado de extrema importância no Brasil, já que surgiu em meio a um contexto de lutas histórico-sociais, marcando a formação do movimento negro contemporâneo no Brasil. O Movimento tornase importante para incentivar o país a discutir sobre as questões raciais, denunciando as desigualdades.

Inserida nessa tentativa do Movimento de reavaliar o papel do negro na história do Brasil, uma das estratégias bem-sucedidas é a atuação direta nas escolas. Muito antes da obrigatoriedade por lei, os movimentos sociais já trabalhavam o tema através de palestras, e produziam materiais didáticos. Maria Raimunda Araujo, conhecida como Mundinha, era presidente do Centro de Cultura Negra no estado do Maranhãona década de 1980, e junto com outros militantes começou a produzir cartilhas sobre a história dos negros, que foram publicadas até em outros estados. (PEREIRA, 2012)

A estratégia de atuar no âmbito da educação foi muito utilizada por organizações negras em vários estados brasileiros. Nesse sentido, a produção de cartilhas como as de Mundinha Araujo para informar não só alunos e professores nas escolas, mas os próprios militantes e a sociedade como um todo, foi uma prática recorrente nas organizações negras de norte a sul do Brasil. E essas cartilhas circulavam nos diferentes estados, em função das redes de relações estabelecidas pelo militantes de todo o país, principalmente na década de 1980. (PEREIRA, 2012, p.42)

A luta dos movimentos negros brasileiros ao longo dos últimos anos teve um papel fundamental tanto na cobrança pelas reinvindicações do papel do negro na história do país, tanto no que diz respeito à educação.

Da mesma maneira, os grupos indígenas participaram ativamente dos movimentos em busca de reconhecimento, delimitação territorial e aceitação cultural. A busca de autonomia diante de órgãos que até então os tutelavam garante aos indígenas a possibilidade de preservação de sua identidade. A Lei 11.645/08, que inclui o estudo da história e das características da cultura indígena nas escolas, foi 
uma grande conquista no reconhecimento do papel do indígena para o país. Essa lei também foi uma grande conquista para os alunos indígenas que estão dentro das escolas, e muitas vezes são submetidos a um currículo que contempla somente a história do branco.

Hoje, portanto, reconhece-se a diversidade cultural que nos constitui. No entanto, na prática educativa, ainda temos um longo percurso para efetivar as propostas de reconhecimento dessa diversidade. Vivemos em uma sociedade ainda preconceituosa, e "para a promoção de uma educaçãointercultural é necessário penetrar no universo de preconceitose discriminações que impregna - muitasvezes com caráter difuso, fluido e sutil - todas as relaçõessociais que configuram os contextos em quevivemos" (CANDAU, 2008, p.53).

Outra importante questão que a legislação menciona é o conhecimento e compreensão da história dos africanos e indígenas anterior à formação da sociedade brasileira resultante do contato com o colonizador europeu. Percebe-se que na maior parte das situações essas populações tem aparição durante 0 período colonial, monárquico ou republicano, o que torna a abordagem simplista e coloca essas populações à margem, como não tendo participação na construção da sociedade brasileira.

A partir da legislação, torna-se obrigatório o estudo e o reconhecimento da história dos africanos buscando suas raízes na África, assim como a compreensão dos grupos indígenas a partir do reconhecimento de suas dinâmicas, vivências e culturas anteriores ao contato com os europeus. Com o trabalho conduzido nessa perspectiva, é possível que essas populações sejam reconhecidas a partir de sua história e de suas próprias percepções. Trazer à tona as vivências dos africanos e indígenas anteriores ao período colonial significa esclarecer que esses indivíduos tinham dinâmicas sociais e culturais próprias, reafirmando o seu protagonismo.

A lei 11.645/08 vem trazer para a escola uma série de questões que antes eram silenciadas, ou simplesmente ignoradas pela comunidade escolar. Essa lei é de fundamental importância para que haja um reconhecimento da pluralidade da sociedade brasileira, que foi e éformada por diferentes histórias e culturas, diferenças estas que também se fazem presentes no espaço escolar. (CRUZ, 2013, p.07)

Entretanto, abordar essas questões na realidade escolar de forma prática implica alguns desafios. Inicialmente, a principal dificuldade que é encontrada refere-se ao sentimento de discriminação em relação a esses grupos sociais, profundamente enraizado na sociedade brasileira, como aponta Candau, apresentando-se de maneira sutil, "através da pluralidade de linguagens, no plano simbólico, e das práticas sociais, e encontram-se carregados muitas vezes de ambiguidades e sutilezas, revestindo-se de grande complexidade". (apud BORGES, 2010, p.73).

Portanto, admitir a complexidade da questão, compreender os processos e as formas discriminatórias, são as principais condições para iniciar o trabalho de maneira significativa, buscando contemplar os objetivos propostos. No entanto, é importante considerar que "pouquíssimo se discutiu sobre uma proposta educativa que considere efetivamente a complexidade cultural do Brasil. Por isso, a elaboração de propostas de trabalho pedagógico sobre este tema encontra dificuldades." (FLEURI, 2001, p.47)

Existem outros obstáculos mais diretamente vinculados ao contexto escolar, como a formação dos professores e o acesso aos recursos didáticos. Os livros didáticos, uma das principais ferramentas utilizadas na sala de aula, na maior parte das vezes apresentam muito pouco dessas populações. Se o índio e o negro estão presentes, estão de forma marginalizada e não como um componente importante para a formação da sociedade nacional.

[...] Tergiversação, que vai ao encontro da estereotipagem, também presente nos livros didáticos estudados, corrobora a ocultação da história e das origens dessas comunidades, o que, infelizmente, não permite - como prevê a legislação brasileira - a promoção do conhecimento e do intercâmbio cultural da história e da cultura desses povos que foram fundamentais para a sociedade brasileira (GOULART;MELO, 2013, p.52). 
Portanto, dentro do próprio contexto educacional, e a partir dos recursos que este fornece aos envolvidos (professores e alunos), encontram-se defasagens com questões cruciais ao objetivo que pretende a legislação. Porém, é possível sim trabalhar essas questões a partir da análise, reflexão e abordagem crítica desses recursos, da mesma forma que é importante buscar a participação e parceria de grupos sociais e culturais assim como da comunidade em que a escola se insere. Relativo aos professores existe a possibilidade da elaboração dos projetos político-pedagógicos que contemplem a diversidade étnica e cultural brasileira, que será estudada nos diferentes componentes curriculares e receberá atenção maior na sala de aula. Trata-se, portanto, de uma mobilização que deve envolver toda a comunidade escolar.

\section{Estudando as culturas indígenas e africanas}

Ao estudar a história e considerar o patrimônio cultural dos grupos indígenas e africanos, pretendese dar visibilidade às distintas culturas, rompendo com um discurso histórico tradicional que se materializou em determinados bens culturais. De acordo com Sandra Pelegrini, "quando falamos em bens culturais, não estamos lidando apenas com objetos, saberes ou celebrações, mas também com as formas do homem se conectar ao lugar onde vive no tempo presente". A partir dessa proposta de considerar a diversidade cultural do Vale do Taquari, no âmbito do Subprojeto História do PIBIDUnivates, foi estruturado um projeto sobre a história e cultura indígena e africana.

A proposta do projeto foi elaborada a partir de uma necessidade da própria escola perante a dificuldade em trabalhar a temática de cultura indígena e afro-brasileira em sala de aula, obrigatória segundo a legislação. A escola solicitou ao grupo de bolsistas do subprojeto História um projeto que abordasse esta temática e que fosse direcionado aos alunos das séries iniciais do Ensino Fundamental, especialmente às turmas de terceiro e quarto anos.
Neste contexto, percebemos que há uma grande dificuldade por parte dos professores que não são da área de História em desenvolver projetos ou momentos que propiciem a aplicação da legislação. A tarefa sempre acaba ficando a cargo dos professores da disciplina de História. Isto provavelmente ocorre devido à falta de formação dos outros professores nesta temática e também pela falta de interesse pelo tema, o que faz com que estes profissionais não busquem informações a respeito.

A partir disso, iniciou-se a elaboração do projeto, que teve duração de quatro meses. Durante este período, os bolsistas se dedicaram a leituras a respeito do tema para conseguirem compreender a proposta da legislação específica, bem como para atender às necessidades da escola. Dentre os assuntos estudados estão a própria legislação, bem como os materiais disponibilizados pelo Ministério da Educação, artigos sobre a relação da temática com alunos das séries iniciais, e também aportes teóricos que tratam da história das etnias indígenas, africanas e afro-brasileiras, além da contribuição cultural deixada pelas mesmas.

Durante esta pesquisa, constatou-se que há uma infinidade de materiais que tratam da temática, muitos deles desenvolvidos pelo próprio Ministério da Educação. Ou seja, a obrigatoriedade da aplicação das leis acontece juntamente com uma série de incentivos e ferramentas gratuitos aos profissionais da educação. Assim, os recursos didáticos estão disponíveis ecabe aos professores buscar essas informações e contribuir para uma educação multicultural, mais inclusiva e que atenda a necessidade da Educação Básica em direcionar o olhar a esses expressivos grupos étnicos, que acabam sendo minimizados diante da sociedade.

Além disso, se faz necessária uma alteração nos currículos escolares, os quais, na maioria das vezes, ainda possuem uma visão eurocêntrica acerca da história trabalhada em sala de aula, tanto nos anos iniciais, quanto nos anos finais do Ensino Fundamental e também no Ensino Médio. Por conseguinte, quando indígenas, africanos e afrobrasileiros são referenciados em sala de aula, são 
tratados de forma estereotipada, pejorativa e discriminatória. Novamente, é preciso que os professores repensem suas grades curriculares para a promoção de uma educação mais abrangente, pontuando a questão em seu plano de trabalho.

É importante salientar que através da educação gera-se a oportunidade de aprender sobre valores culturais, mantendo-nos em contato com diversas práticas culturais. A escola é um lugar relevante para este processo, para a valorização das características culturais de cada grupo estudado, mas nem sempre isso ocorre de maneira efetiva. Trata-se de uma questão importante, sobretudo em um país constituído por uma diversidade de grupos bastante significativa, e nem sempre essa diversidade é abordada e explorada em sala de aula, apesar de a escola ser composta igualmente por essa diversidade social e cultural (CHAGAS, 2008).

Em vez de preservar uma tradição monocultural,a escola está sendo chamada a lidar com a pluralidadede culturas, reconhecer os diferentes sujeitos socioculturaispresentes em seu contexto, abrir espaços para amanifestação e valorização das diferenças. E essa, anosso ver, a questão hoje posta. A escola sempre tevedificuldade em lidar com a pluralidade e a diferença.Tende a silenciá-las e neutralizá-las. Sente-se mais confortávelcom a homogeneização e a padronização. Noentanto, abrir espaços para a diversidade, a diferença,e para 0 cruzamento de culturas constitui o grande desafioque está chamada a enfrentar. (MOREIRA, 2003, p.161)

Embora exista a Lei 11.645, sabe-se que nem todos os profissionais da educação fazem seu papel de forma efetiva. Tratando-se sobre a história e cultura indígena e africana, o que ocorre frequentemente é a abordagem destes temas somente nos dias de comemoração ao "dia do índio" ou "consciência negra". Fora destas datas, as abordagens são poucas ou então inseridas em um conteúdo rígido da grade curricular. O que precisamos no ambiente escolar é estimular o contato com as diferentes culturas.

A relação entre culturas diferentes, entendidas como contextos complexos, produz confrontos entre visões de mundo diferentes. A interação com uma cultura diferente contribui para que uma pessoa ou um grupo modifique o seu horizonte de compreensão da realidade, na medida em que lhe possibilita compreender ou assumir pontos de vista ou lógicas diferentes de interpretação da realidade ou de relação social. (FLEURI, 2001, p.53)

Assim sendo, buscou-se desenvolver um projeto que respondesse a essas deficiências da escola, tratando as populações indígenas, africanas e afro-brasileiras de uma forma heterogênea, ressaltando suas singularidades e trabalhando para a desconstrução de estereótipos, numa perspectiva intercultural.

Assim, em nível das práticas educacionais, a perspectiva intercultural propõe novas estratégias de relação entre sujeitos e entre grupos diferentes. Busca promover a construção de identidades sociais e o reconhecimento das diferenças culturais. Mas, ao mesmo tempo, procura sustentar a relação crítica e solidária entre elas. (FLEURI, 2001, p.49)

Como o grupo de bolsistas não atuava com alunos da primeira etapa do Ensino Fundamental, foi preciso uma preparação para trabalhar com este público, o qual ainda não possui um ensino dividido por disciplinas, e sim um conjunto de todas as áreas do conhecimento que ficam a cargo de um único professor.Portanto, percebeu-se que o projeto deveria estar relacionado coma realidade dos alunos, buscando apresentar a diversidade cultural presente no diaadia dessas crianças.

Também foi importante saber que é nesse período que as crianças constituem sua identidade e formam sua personalidade, sendo que isso é influenciado pelas informações adquiridas ao longo desse processo. Assim, o professor precisa atentar para o estudo da diversidade e do reconhecimento das diferenças, partindo de informações que estimulem o diálogo e o respeito.

Informações que reproduzem novas formas de ver e compreender as pessoas enquanto sujeitos diferentes, que precisam ser respeitados e valorizados em meio à suas diferenças. Ou seja, as crianças precisam desde cedo construir uma nova visão sobre o mundo que superem os estereótipos e os preconceitos construídos pelo pensamento 
ocidental homogeneizador (MOTA; MACHADO; LIMA, 2010, p.02).

Consequentemente, o objetivo geral do projeto foi conhecer a cultura afro-brasileira e indígena a partir de aspectos históricos, sociais e étnicoculturais, compreendendo, assim, a formação social brasileira a partir de sua diversidade, priorizando o respeito entre os diferentes grupos que compõem a sociedade brasileira.Os objetivos específicos foram perceber as características internas dos grupos indígenas e africanos, assim como as diferenças entre um grupo e outro; entender o processo histórico pelo qual esses grupos passaram, relacionando com a atual realidade dessas etnias; analisar a influência cultural desses grupos na cultura brasileira ao longo da história, a partir de hábitos que permanecem até hoje e incentivar o respeito e a não discriminação entre os diferentes grupos que compõem a cultura brasileira. O projeto foi intitulado Cultura Indígena e Afro-brasileira nos Anos Iniciais, e estruturado a partir da organização de oficinas.

A primeira oficina proposta para os alunos foi sobre a cultura indígena. Os alunos permaneceram organizados em círculo, sentados no chão,em torno de um papel pardo. De uma caixa foram retiradas fichas com interrogações sobre a temática que norteou as falas dos bolsistas e alunos. Os alunos foram dialogando sobre a denominação e utilização do termo "indígenas" (em oposição à singularidade de “índio")e conhecendo os diversos grupos indígenas presentes no território brasileiro.

Houve uma abordagem sobre quais elementos de herança cultural foram deixados pelos indígenas e incorporados pela sociedade contemporânea. Conforme as colocações dos bolsistas e dos alunos, foi organizado sobre o papel pardo um mapa conceitual a partir da palavra "INDÍGENA". Destacaram-se elementos como o chimarrão, churrasco, banho, maquiagem, vocabulário, entre outras características. Além do cartaz, foram abordados temas atuais, como por exemplo, a relação dos indígenas com as tecnologias, e as características culturais de alguns grupos.
Nessa oficina ainda trabalhou-se com 0 patrimônio imaterial do grupo indígena Guarani, através da confecção de vasilhas de cerâmica utilizando a técnica do acordelado. Nesta etapa, desde a parte teórica até a prática, os alunos demonstraram interesse sobre o assunto. Houve também a participação dos professores da escola.

Além da oficina mencionada, foram desenvolvidas três práticas sobre a cultura afrobrasileira. Todasas turmas participaram das três oficinas que foramdesenvolvidas.A oficina de Capoeira, ministrada pela Professora de Educação Física Rita Quadros, teve como objetivo através da prática aproximar os alunos dos elementos culturais do grupo. Houve a abordagem cultural da dança, explicando a origem da prática, apresentando os instrumentos específicos e realizando-se a Roda de Capoeira.

A Oficina Histórica procurou desenvolver atividades relacionadas a alguns grupos étnicos africanos e o processo de deslocamento dos mesmos para o Brasil. Foi confeccionado um grande mapa, com o contorno do continente Africano e a divisão étnica do território, evidenciando o pluralismo cultural da África. Procurou-se desenvolver a perspectiva de formação da família escrava e da trajetória nas terras brasileiras, evidenciando a formação social e as formas de resistência dos quilombolas.

Ao longo das oficinas, foram realizadas diversas atividades lúdicas, além da utilização de vídeos, jogos e atividades que estimularam a movimentação corporal. A Oficina Cultural proporcionou a participação em algumas dinâmicas que permitiram a vinculação do tema trabalhado com o desenvolvimento de habilidades de coordenação e atenção. Nessa oficina foram praticados alguns jogos:

- 1a Terra-mar (Moçambique). Foi feita uma longa reta riscada no chão. De um lado se escreve "Terra" e do outro "Mar". No início todas as crianças ficam no mesmo lado. Ao ouvirem "mar" todos devem pular para este lado. Quem pular para o lado errado sai do jogo. O último a permanecer sem errar, vence.

- 2 ${ }^{a}$ Meu querido bebê (Nigéria). Um jogador é escolhido e sai da sala. Os outros escolhem outro 
jogador para ser o "bebê". O "bebê" deita no chão e os outros jogadores desenham o seu contorno com giz. O "bebê" se junta aos outros jogadores. O jogador que saiu volta e tenta determinar quem é o "bebê", baseado no contorno desenhado no chão. Acertando ou não, esse colega escolherá outro jogador para sair da sala e ser o próximo a adivinhar que é o "bebê" do grupo.

- 3므 Tabuleiro Yoté. O jogoé muito popular em toda a região oeste da África (particularmente no Senegal). Foi jogado em duplas, e permite o desenvolvimento de raciocínio lógico e sentido de observação.

Todo o material utilizado nos jogos foi produzido pelos bolsistas, e cada uma das atividades foi realizada por todos os alunos interessados. Conheceu-se a origem e as regras dos jogos, vinculados com as tradições e costumes dos povos africanos, estabelecendo-se um comparativo com os jogos conhecidos no Brasil.

\section{Considerações finais}

Após a finalização do Projeto Cultura Indígena e Afro-brasileira nos Anos Iniciais constatou-seque o objetivo proposto foi alcançado. Tendo em vista que os alunos estiveram envolvidos com as oficinas e práticas propostas, a ponto de expor suas opiniões e reflexões sobre o tema abordado, reavaliaram-se diversos elementos sobre os grupos indígenas e africanos, além dos alunos compreenderem e conhecerem mais sobre a sua cultura.

Com estas oficinas, consideramos que a inserção da temática indígena, africana e afrobrasileira no currículo escolar pode contribuir para uma aproximação da cultura destes grupos com a nossa sociedade, incentivando o respeito e o contato intercultural. Evidencia-se a presença de povos que constituem a nossa sociedade brasileira, que resistiram a distintos processos de controle e que devem ser respeitados pelo seu valor cultural e histórico (BITIOLI; TONIOSSO, 2013). Trata-se de grupos que não foram reconhecidos em sua historicidade em função dos significados atribuídos à população indígena, mestiça e negra ao longo da formação social brasileira. Ao analisar esse processo de invisibilização, entende-se os movimentos que não permitiram 0 seu reconhecimento antes da Constituição de 1988.

Conforme anota Dominique Poulot (2001, p.05), o patrimônio tem a ver com interpretação e, desse modo, é concebido como elaboração de significados. Nesses termos, a história do patrimônio cultural pode ser caracterizada como um inventário de sentidos da noção de patrimônio (BABELON \& CHASTEL, 1994). A consequência disso é reconhecer que o patrimônio cultural não se define como dado, mas como construção social e histórica e que se oferece à interpretação histórica". (KNAUSS, 2014, p.16). A história e cultura indígenas e africanas no Brasil precisam, portanto, ser conhecidas a partir dos sentidos que lhes foram atribuídos e das práticas dos próprios grupos.

Propostas como essas questionam o discurso e as práticaseurocêntricas, homogeneizadoras e monoculturais dos processos sociaise educativos e colocam no cenário público questões referidas àconstrução de relações étnico-raciais nos contextos latino-americanos.Desvelam 0 racismo e as práticas discriminatórias que perpassam ocotidiano das nossas sociedades e instituições educativas e promovemo reconhecimento e valorização das diferenças culturais, componentesfundamentais para a promoção de uma educação intercultural. (CANDAU, RUSSO, 2010, p.160)

As atividades que continuam sendo desenvolvidas pelos bolsistas pretendem redefinir a natureza e o valor do patrimônio cultural da região, contemplando todos os grupos sociais e as distintas identidades constituídas. Pontuando-se a diversidade cultural, e promovendo a produção de novos sentidos patrimoniais, pretende-se uma abordagem dos processos culturais.

Ao reconhecermos que as políticas de memória e preservação do patrimônio cultural acabam produzindo uma imagem para o passado, pretende-se alterar a percepção de que determinados grupos sociais não tiveram participação importante na constituição identitária das cidades do Vale do 
Taquari. "Dentro desse contexto, qualquer patrimônio é entendido como uma escolha política e não como um dado natural, objetivo e incontestável" (CARVALHO, FUNARI, p.10). Desnaturalizando a ideia de que somente os imigrantes europeus deixaram marcas na cultura regional, pretende-se contribuir para a afirmação das demais identidades étnicas desse espaço social, promovendo as trocas interculturais.

\section{Referências}

ABREU, Regina e CHAGAS, Mário (Orgs.). Memória e patrimônio: ensaios contemporâneos. Rio de Janeiro: DP\&A, 2003.

BARRETO, Euder Arrais et. al. (Org.). Patrimônio Cultural e Educação: artigos e resultados. Goiania: Gráfica Talento, 2008.

BITIOLI, Michele; TONIOSSO, José Pedro. História e Cultura afro-brasileira no currículo escolar. Revista Fafibe On-Line, São Paulo, ano VI, n.6, p. 57-66, nov. 2013.

BORGES, Elisabeth Maria de Fátima. A Inclusão da História e da Cultura Afro-brasileira e Indígena nos Currículos da Educação Básica. Revista Mest. Hist., Vassouras, v. 12, n. 1, p. 71-84, jan./jun., 2010.

BRASIL. Constituição (1988). Constituição da República Federativa do Brasil: promulgada em 5 de outubro de 1988. Organização do texto: Juarez de Oliveira. 4. ed. São Paulo: Saraiva, 1990. (Série Legislação Brasileira).

CANDAU, Joel. Memória e identidade. São Paulo: Contexto, 2012.

CANDAU, Vera Maria. Direitos Humanos, Educação e Interculturalidade: as tensões entre igualdade e diferença. Revista Brasileira de Educação. V.13, n.37, jan-abr 2008, p.45-57.

CANDAU, Vera Maria. RUSSO, Kelly. Interculturalidade e Educação na América Latina. Uma construção plural, original e complexa. Revs. Diálogo Educ., Curitiba, v.10, n.29, jan-abr 2010, p.151-169.

CANEN, Ana; OLIVEIRA, Ângela M. A. de. Multiculturalismo e currículo em ação. Revista Brasileira de Educação. Set/Out/Nov/Dez 2002 no 21. 2002.

CHAGAS, Waldeci Ferreira. Formação docente e cultura afro-brasileira. Revista África e Africanidades, Rio de Janeiro, ano I, n.3, nov. 2008.
CHAGAS, Mário. Cultura, patrimônio e memória. In: Ciências e Letras, n. 31, jan-jun 2002. Porto Alegre: Editora da PUC, 2002.

CHAUÍ, Marilena. Cidadania cultural: $O$ direito à cultura. São Paulo: Editora da Fundação Perseu Abramo, 2006

CHOAY, Françoise. A alegoria do Patrimônio. Lisboa: Edições 70, 2000.

CRUZ, Caroline Silva; JESUS, Simone Silva.Lei 11.645/08:A escola, as relações étnicas e culturais e o ensino de história - algumas reflexões sobre essa temática no PIBID. XXVII Simpósio Nacional de História, 2013.

FLEURI, Reinaldo M. Desafios à Educação Intercultural no Brasil. Educação, Sociedade e Cultura, n.16, 2001, p.45-62

FLEURI, Reinaldo M. Intercultura e Educação. Revista Grifos, n. 15, p. 16 - 47, maio. 2003.

FONSECA, Maria Cecília Londres. O patrimônio em processo: trajetória da política federal da preservação no Brasil. Rio de Janeiro: Ed.UFRJ/MINC-IPHAN, 2005.

KNAUSS, Paulo. Usos do passado e patrimônio cultural. In: REINHEIMER, Dalva. Patrimônio Histórico nas comunidades teuto-brasileiras. São Leopoldo: Oikos, 2014.

KRETZMANN, Carolina Giordani.Multiculturalismo e diversidade cultural: comunidades tradicionais e a proteção do patrimônio comum da humanidade. Dissertação (Mestrado em Direito). Caxias do Sul: UCS, 2007.

LIMA, Elmo de Souza; MACHADO, Darlene Lira; MOTA, Carla Carolina França. Currículo e diversidades culturais da Educação Infantil. Disponível em: http://www.ufpi.br/subsiteFiles/ppged/arquivos/files/VI. encontro.2010/GT.8/GT_08_05_2010.pdf. Acesso em: 22 de junho de 2015 .

LORENZET, Deloíze; CARPENEDO, Vera Danair. Multiculturalismo, Intercultura $e$ as Políticas Afirmativas. IX ANPED SUL: Seminário de Pesquisa em Educação da região sul. 2012. Disponível em: http://www.fpl.edu.br/enade2015/pdfs/novo_texto_mul ticulturalismo.pdf

MOREIRA, Antonio Flavio; CANDAU, Vera M. Educação escolar e cultura(s): construindo caminhos. Revista Brasileira de Educação, n.23, 2003, p.156168.

PELEGRINI, Sandra. O patrimônio cultural no discurso e na lei: trajetórias do debate sobre apreservação no Brasil. Patrimônio e Memória Revista Eletrônica, v. 2, n. 2, p. 1-24, Assis - São Paulo: UNESP - FCLAs - CEDAP, 2006 
PELEGRINI, Sandra. A salvaguarda e a sustentabilidade do patrimônio imaterial brasileiro: impasses e jurisprudências. In: FUNARI, Pedro Paulo A.; PELEGRINI, Sandra C. A.; Rambelli, Gilson. Patrimônio Cultural e Ambiental: questões legais e conceituais. São Paulo: Annablume/FAPESP, 2008.

PELEGRINI, Sandra. A gestão do patrimônio imaterial brasileiro na contemporaneidade. História[online]. 2008, vol.27, n.2, pp. 145-173.

PELEGRINI, Sandra; FUNARI, P. O que é patrimônio cultural imaterial. São Paulo: Brasiliense, 2008.

POULOT, Dominique. Uma História do Patrimônio no Ocidente. São Paulo: Estação Liberdade, 2009.

PESSÔA, Jacira Maria de Medeiros. Leis 10.639/03 e 11.645/08: (Re)construindo a história afro-brasileira e indígena. IV Colóquio de História, UNICAP, nov., 2010.

GOULARTE, Raquel da Silva; MELO, Karoline Rodrigues. A lei 11.645/08 e a sua abordagem nos livros didáticos do ensino fundamental. Revista Entretextos, Londrina, v.13, no 02, p. 33-54, jul./dez., 2013.

PEREIRA, AlmicarAraujo. A Lei 10.639/03 e o movimento negro: aspectos da luta pela "reavaliação do papel do negro na história do Brasil". Cadernos de História, Belo Horizonte, v.12, n. 17, ำ sem. 2011.

SACAVINO, Susana. Interculturalidade e educação: desafios para a reinvenção da escola. XVI ENDIPE Encontro Nacional de Didática e Práticas de Ensino UNICAMP - Campinas - 2012.

SEYFERTH, Giralda. Construindo a nação: hierarquias raciais e o papel do racismo na política de imigração e colonização. In: MAIO, Marcos; SANTOS, Ricardo (org.). Raça, Ciência e Sociedade. Rio de Janeiro: Fiocruz, 1996.

VIOTTI DA COSTA, Emilia. O mito da democracia racial no Brasil. In: Da Monarquia à República: momentos decisivos. São Paulo: Editora Unesp, 1999, p.365-384. 